\title{
A gestão da demanda em cadeias de suprimentos: uma abordagem além da previsão de vendas
}

\section{Demand management on supply chains: more than sales forecast}

\author{
Daniela de Castro Melo' \\ Rosane Lúcia Chicarelli Alcântara²
}

\begin{abstract}
Resumo: A gestão da demanda emerge nos campos de conhecimentos da gestão da cadeia de suprimentos e de marketing. Busca-se a rápida e adequada integração das necessidades originadas do mercado na direção dos fornecedores, de modo a balancear e alinhar estrategicamente a demanda com a capacidade operacional ao longo da cadeia de suprimentos. O objetivo deste artigo é propor uma abordagem conceitual para a implantação de um processo efetivo de gestão da demanda em cadeias de suprimentos fornecendo uma visão mais ampla da gestão da demanda como um processo integrado e não uma atividade isolada ou resumida à previsão de vendas. Para o desenvolvimento desta abordagem, realizou-se uma ampla revisão da literatura, usando a metodologia da revisão sistemática de literatura. Os resultados apontam que o primeiro passo da abordagem conceitual consiste na compreensão do mercado por meio da análise das capacidades, restrições, oportunidades dos ambientes interno e externo à empresa. Este conhecimento ditará as diretrizes e práticas estratégicas e operacionais da organização. O processo de gestão da demanda envolve um time multifuncional composto por integrantes de diversos níveis e setores da organização, bem como representantes estratégicos da cadeia de suprimentos (fornecedores e clientes). Este time será responsável pelo desenvolvimento conjunto das previsões de vendas, da elaboração, execução e acompanhamento do plano de negócio. Para isto, os agentes internos e externos da cadeia precisam ter uma orientação para a cadeia de suprimentos. Uma implementação bem conduzida desta abordagem pode melhorar o nível de serviço prestado ao cliente e gerar benefícios substanciais para os resultados financeiros da empresa.
\end{abstract}

Palavras-chave: Gestão da demanda. Gestão da cadeia de suprimentos. Revisão sistemática.

\begin{abstract}
Demand management emerges in knowledge fields of supply chain management and marketing. It aims at rapid and appropriate integration of the needs arising from the market towards the suppliers in order to balance the demand and strategically align it with the operational capacity throughout the supply chain. The aim of this paper is to propose a conceptual approach to implement an effective process of demand management in supply chains and provide a broader view of demand management as an integrated process and not an isolated activity or just as sales forecasting. To develop this approach, an extensive review of literature was conducted using the methodology of systematic literature review. The results indicate that the first step of the conceptual approach is the understanding of the market by analyzing the capabilities, constraints, and opportunities for internal and external environments to the enterprise. This knowledge will dictate the strategic and operational policies and practices of the organization. The process of demand management involves a multi-functional team composed of members of various levels and sectors of the organization as well as representatives of the strategic supply chain (suppliers and customers). This team will be responsible for the joint development of sales forecasts and the business plan development, implementation, and monitoring. Hence, the internal and external actors in the chain must have a supply chain orientation. A well-managed implementation of this approach can improve the level of customer service and generate substantial benefits for the company's financial results.
\end{abstract}

Keywords: Demand management. Supply chain management. Systematic literature review.

\section{Introdução}

A gestão da demanda é um tema emergente no campo de conhecimento da gestão da cadeia de suprimentos. O que se busca com a gestão da demanda é a rápida e adequada integração das necessidades originadas do mercado na direção dos fornecedores, de modo a balancear e alinhar estrategicamente a demanda com a capacidade operacional ao longo da cadeia de suprimentos. O alinhamento da demanda na cadeia de suprimentos enfrenta dificuldades progressivas tais como a falta de precisão nas informações, entre outras, provocando ineficiência no atendimento a clientes, redução do giro de estoque e alto índice de obsolescência agravada pela grande diversidade de produtos.

\footnotetext{
${ }^{1}$ Faculdade de Gestão e Negócios, Universidade Federal de Uberlândia - UFU, Av. João Naves de Ávila, 2121, Bloco F, CEP 38408-100, Uberlândia, MG, Brasil, e-mail: daniela_c_melo@yahoo.com.br

${ }^{2}$ Universidade Federal de São Carlos - UFSCar, Rod. Washington Luis Km, 235, CEP 13560-000, São Carlos, SP, Brasil, e-mail: rosane@dep.ufscar.br
} 
Alguns autores destacaram a necessidade de pesquisas sobre a gestão da demanda (ADEBANJO, 2009; KAIPIA; KORHONEN; HARTIALA, 2006; SIMATUPANG; SRIDHARAN, 2002; TAYLOR, 2006; TAYLOR; FEARNE, 2006) após verificarem, por meio de pesquisas empíricas, que a falta de alinhamento entre oferta e demanda era um problema crônico e caro em várias cadeias de suprimentos com perdas devido a desperdícios, à falta ou ao excesso de estoques, a baixas margens de lucro.

Assim, o atendimento das necessidades dos consumidores deve ser sincronizado com a capacidade produtiva da empresa. A coordenação eficiente entre marketing e a gestão da cadeia de suprimentos pode resultar em maior vantagem competitiva. Sinergias entre marketing e a gestão da cadeia de suprimentos (SCM) são reconhecidas tanto na literatura de marketing (ACHROL, 1991, 1997; ACHROL, KOTLER, 1999; FLINT, 2004; JUTTNER; CRHISTOPHER; BAKER, 2007; KUMAR; SCHEER; KOTLER, 2000; SHETH; SISODIA; SHARAN, 2000; SRIVASTAVA; SHERVANI; FAHEY, 1999; WALTERS; RAINBIRD, 2004) como também na literatura da SCM (ALVARADO; KOTZAB, 2001; BECHTEL; JAYARAM, 1997; COOPER; LAMBERT; PAGH, 1997; FISHER, 1997; LAMBERT; COOPER, 2000; MENTZER et al., 2001; MIN; MENTZER, 2000; RAINBIRD, 2004; SVENSSON, 2002).

A maioria destes estudos propõe coordenação entre certas atividades de marketing e suprimentos para explorar sinergias específicas, enquanto outras pesquisas defendem uma abordagem de gestão em conjunto intitulada gestão da cadeia de demanda (Demand Chain Mangement-DCM), ou simplesmente gestão da demanda, em que os processos de criação e atendimento da demanda são coordenados de uma forma mais completa (HILLETOFTH; ERICSSON, 2007; JUTTNER; CRHISTOPHER; BAKER, 2007; RAINBIRD, 2004; WALTERS, 2006; WALTERS; RAINBIRDS, 2004).

Há pouca informação disponível sobre a gestão da demanda em cadeias de suprimentos (ADEBANJO, 2009; TAYLOR, 2006; TAYLOR; FEARNE, 2006). Segundo Hilletofth, Ericsson e Christopher (2009), a gestão da demanda não é modismo, é uma forma das empresas alcançarem um benefício substancial focando no cliente, além de enfatizar a necessidade de colaboração entre marketing e SCM para a criação de valor. Porém, os autores ressaltam que a aplicação da gestão da demanda é ainda muito recente, necessitando de mais pesquisas que abordem o tema.

Portanto, o objetivo deste artigo é propor uma abordagem conceitual para a implantação de um processo efetivo de gestão da demanda em cadeias de suprimentos, fornecendo uma visão mais ampla da gestão da demanda como um processo integrado e não uma atividade isolada ou resumida à previsão de vendas. Para o desenvolvimento desta abordagem, realizou-se uma revisão sistemática da literatura (TRANFIELD; DENYER; SMART, 2003; TRANFIELD et al., 2004) sobre gestão da demanda.

Este artigo está estruturado em três partes. Inicialmente é discutido o método de pesquisa abrangendo os estágios da revisão sistemática da literatura. No próximo tópico, são apresentados os resultados desta revisão descrevendo as definições e abordagens da gestão da demanda, como também a estrutura conceitual para sua gestão. A última parte é dedicada às conclusões.

\section{Método}

O objetivo da revisão da literatura é permitir ao pesquisador mapear e analisar o território intelectual existente sobre determinado tema e especificar a questão de pesquisa para desenvolver mais profundamente um campo do conhecimento. Uma alternativa para a revisão da literatura é a sua revisão sistemática (TRANFIELD; DENYER; SMART, 2003).

A revisão sistemática é uma metodologia que utiliza como fonte de dados a literatura sobre determinado tema, seleciona e avalia contribuições, analisa e sintetiza dados. Descreve as evidências de forma a permitir conclusões claras a serem alcançadas sobre o que já se conhece e sobre o que não se conhece sobre o assunto em questão (DENYER; TRANFIELD, 2009).

Assim, esta pesquisa está dividida em três estágios: planejamento da revisão, condução da revisão e apresentação dos resultados (Quadro 1).

A seguir será feita uma descrição dos estágios que constituem o processo de elaboração de um estudo de revisão sistemática.

\subsection{Estágio I: planejamento da revisão}

A proposta desta revisão é identificar os conceitos de gestão da demanda sob a perspectiva da gestão da cadeia de suprimentos e suas abordagens. Assim, foi elaborado um protocolo de pesquisa contendo como encontrar os estudos e os critérios de inclusão dos artigos (Quadro 2).

Quadro 1. Estágios da revisão sistemática da literatura.

\begin{tabular}{|l|}
\hline \multicolumn{1}{|c|}{ Estágio I: Planejamento da revisão } \\
\hline Fase 1: Proposta de revisão \\
Fase 2: Desenvolvimento de um protocolo de revisão \\
\hline \multicolumn{1}{|c|}{ Estágio II: Condução da revisão } \\
\hline Fase 3: Seleção dos estudos \\
Fase 4: Síntese dos dados \\
\hline \multicolumn{1}{|c|}{ Estágio III: Apresentação dos resultados } \\
\hline Fase 5: Análise dos dados \\
Fase 6: Discussões e conclusões \\
\hline
\end{tabular}

Fonte: Adaptado de Tranfield, Denyer e Smart (2003, p. 214); Tranfield et al. (2004, p. 380). 
Quadro 2. Protocolo de pesquisa.

1- Acesso aos artigos e livros clássicos sobre 'gestão da cadeia de suprimentos'.

2- Acesso aos capítulos de livros sobre Gestão da Demanda: Croxton et al. (2008); Mentzer e Moon (2005); Mentzer et al. (2007), Pires (2009).

3- Acesso às bases de dados Science Direct, Emerald e Wiley-Blackwell. Busca avançada utilizando os termos 'demand management', 'demand supply chain', 'demand chain', 'demand chain management' no título do artigo ou nas palavras-chave.

4- Acesso às bibliotecas digitais de Teses e Dissertações. Busca avançada utilizando o termo 'gestão da demanda' no título ou nas palavras-chave.

5- Acesso aos principais periódicos nacionais nas áreas de Administração e de Engenharia de Produção. Busca avançada utilizando o termo 'gestão da demanda' no título do artigo ou nas palavras-chave.

6- Acesso aos anais dos principais eventos e simpósios nas áreas de Administração e de Engenharia de Produção. Busca utilizando o termo 'gestão da demanda'.

\subsection{Estágio II: condução da revisão}

A revisão da literatura iniciou-se pelo estudo do tema gestão da cadeia de suprimentos, acessando os livros nacionais e internacionais, como também artigos internacionais clássicos sobre o tema.

Durante a seleção dos estudos, foram avaliados os títulos e os resumos que contemplassem a gestão da demanda em cadeias de suprimentos. Foram excluídos os capítulos de livros, artigos, teses ou dissertações que contemplavam somente a previsão de demanda.

Dentre os livros internacionais e nacionais sobre gestão da cadeia de suprimentos, foram consultados os capítulos referentes à gestão da demanda.

As bases de dados eletrônicas Science Direct, Emerald e Wiley-Blackwell disponíveis por meio do Portal de Periódicos da Capes foram consultadas retrospectivamente até o ano de 2010. Efetuou-se uma busca avançada utilizando os termos 'demand management', 'demand supply chain', 'demand chain' 'demand chain management' no título do artigo ou nas palavras-chave. Nesta busca, foram considerados como filtros 'todos os anos' (disponíveis na base de dados até o ano de 2010) e 'apenas os jornais'. O Quadro 3 mostra o número de artigos gerados na pesquisa por base de dados e por termo.

Assim, foram avaliados cerca de 200 artigos. Destes, foram selecionados 47 artigos que tratavam do conceito, e/ou das abordagens, e/ou dos desafios da gestão da demanda sob a perspectiva da gestão da cadeia de suprimentos. As bases de dados e seus respectivos periódicos nos quais foram localizados os artigos selecionados podem ser visualizados por meio do Quadro 4.

A leitura dos artigos selecionados do Quadro 4 indicou a necessidade de pesquisar outros artigos em bases de dados diferentes. Assim, foram consultados mais 18 artigos (Quadro 5).

As pesquisas nacionais englobaram o acervo de bibliotecas digitais de teses e dissertações, publicações em periódicos e anais de eventos (encontros e simpósios) nas áreas de Engenharia de Produção e de Administração.

As bibliotecas digitais acessadas foram: Biblioteca Digital Brasileira de Teses e Dissertações, Pesquisa de
Quadro 3. Número de artigos gerados na pesquisa por base de dados e por termo.

\begin{tabular}{|l|c|c|c|}
\hline \multirow{2}{*}{$\begin{array}{c}\text { Busca avançada: } \\
\text { termos no título } \\
\text { do artigo ou nas } \\
\text { palavras-chave } \\
\text { ('todos os anos' e } \\
\text { 'apenas nos jornais') }\end{array}$} & \multicolumn{3}{|c|}{$\begin{array}{c}\text { Número de artigos } \\
\text { por base de dados }\end{array}$} \\
\cline { 2 - 4 } & $\begin{array}{c}\text { Science } \\
\text { Direct }\end{array}$ & Emerald & $\begin{array}{c}\text { Wiley- } \\
\text { Blackwell }\end{array}$ \\
\hline Demand management & 100 & 47 & 37 \\
\hline Demand supply chain & 100 & 14 & 5 \\
\hline Demand chain & 100 & 11 & 6 \\
\hline $\begin{array}{l}\text { Demand chain } \\
\text { management }\end{array}$ & 48 & 6 & 1 \\
\hline
\end{tabular}

Teses e Dissertações (CAPES), Biblioteca Digital de Teses e Dissertações da USP e Biblioteca Comunitária UFSCar. Foi realizada uma busca avançada utilizando o termo 'gestão da demanda' no título ou nas palavraschave, identificando quatro registros. Destes, apenas uma tese e uma dissertação foram selecionadas. Além disso, por sugestões de pesquisadores, foram pesquisadas duas dissertações referentes à 'gestão da demanda' na biblioteca da Universidade Metodista de Piracicaba (UNIMEP).

A base de dados Scielo foi consultada para a busca de artigos nos periódicos: Produção e Gestão \& Produção. Nenhum registro foi identificado com o termo 'gestão da demanda' no título do artigo ou no resumo (não há filtro por palavra-chave). Também não foi identificado nenhum registro com o termo 'gestão da demanda' no título do artigo ou nas palavras-chave da RAUSP (Revista de Administração da Universidade de São Paulo); e utilizando o termo 'gestão da demanda' nas palavras-chave (a busca permite o filtro somente por autor e por palavra-chave) no periódico RAE (Revista de Administração de Empresas).

Nos encontros e simpósios, foram identificados 13 artigos que continham o termo 'gestão da demanda' no título. Foram selecionados quatro artigos para análise (Quadro 6).

Os capítulos de livros, artigos, teses e dissertações incluídos na revisão sistemática foram sintetizados, 
Quadro 4. Bases de dados e seus respectivos periódicos nos quais foram localizados os artigos selecionados.

\begin{tabular}{|c|c|c|}
\hline Base de dados & $\mathbf{N}^{\mathbf{0}}$ artigos & Periódicos internacionais \\
\hline \multirow{4}{*}{ Emerald (34 artigos) } & 1 & European Business Review \\
\cline { 2 - 3 } & 2 & Industrial Management and Data Systems \\
\cline { 2 - 3 } & 1 & Integrated Manufacturing Systems \\
\cline { 2 - 3 } & 1 & Journal of Business and Industrial Marketing \\
\cline { 2 - 3 } & 1 & Journal of Consumer Marketing \\
\cline { 2 - 3 } & 1 & Journal of Contemporary Hospitality Management \\
\cline { 2 - 3 } & 1 & Journal of Enterprise Information Management \\
\cline { 2 - 3 } & 1 & Journal of Logistics Management \\
\cline { 2 - 3 } & 1 & Journal of Operations and Production Management \\
\cline { 2 - 3 } & 10 & Journal of Physical Distribution and Logistics Management \\
\hline \multirow{5}{*}{ Science Direct (12 artigos) } & 2 & Supply Chain Management \\
\cline { 2 - 3 } & 2 & European Management Journal \\
\cline { 2 - 3 } & 4 & European Journal of Purchasing \& Supply Management \\
\cline { 2 - 3 } & 1 & Industrial Marketing Management \\
\cline { 2 - 3 } & 1 & Journal of Operations Management \\
\cline { 2 - 3 } & 2 & Journal of Production Economics \\
\hline \multirow{5}{*}{ Wiley-Blackwell } & 1 & British Journal of Marketing \\
\hline
\end{tabular}

Quadro 5. Bases de dados e seus respectivos periódicos nos quais foram localizados os demais artigos selecionados.

\begin{tabular}{|l|c|l|}
\hline \multicolumn{1}{|c|}{ Base de dados } & $\mathbf{N}^{\mathbf{0}}$ artigos & \multicolumn{1}{|c|}{ Periódicos internacionais } \\
\hline Academy of Marketing Science & 3 & Journal of the Academy of Marketing Science \\
\hline Gale & 3 & Harvard Business Review \\
\hline Informs & 1 & Management Science \\
\hline Wilson & 3 & Journal of Marketing \\
\hline \begin{tabular}{l} 
Outras bases não disponíveis pelo \\
Portal Capes: acesso por meio da \\
Michigan State University ou School of \\
Management at Cranfield University \\
\cline { 2 - 3 } (8 artigos)
\end{tabular} & 1 & Food Logistics \\
\cline { 2 - 3 } & 1 & Journal of Business Logistics \\
\cline { 2 - 3 } & 1 & Conradi Research Review \\
\cline { 2 - 3 } & 1 & Journal on Chain and Network Science \\
\hline
\end{tabular}

Quadro 6. Número de artigos identificados e selecionados em eventos e simpósios.

\begin{tabular}{|c|c|c|}
\hline $\begin{array}{l}\text { Encontros e } \\
\text { simpósios }\end{array}$ & $\begin{array}{l}\mathrm{N}^{0} \text { de } \\
\text { artigos }\end{array}$ & $\begin{array}{l}\mathrm{N}^{0} \text { de artigos } \\
\text { selecionados }\end{array}$ \\
\hline ENEGEP (Encontro Nacional de Engenharia de Produção) - de 2000 a 2009 & 10 & 2 \\
\hline SIMPEP (Simpósio de Engenharia de Produção) - de 2000 a 2009 & 2 & 1 \\
\hline $\begin{array}{l}\text { SIMPOI (Simpósio de Administração da Produção, Logística e Operações } \\
\text { Internacionais) - de } 2005 \text { a } 2009\end{array}$ & 1 & 1 \\
\hline $\begin{array}{l}\text { ENANPAD (Encontro da Associação Nacional de Pós-Graduação e Pesquisa } \\
\text { em Administração) - todos os anos }\end{array}$ & 0 & 0 \\
\hline
\end{tabular}

destacando-se os pontos principais de cada um. $\mathrm{O}$ próximo tópico apresenta os resultados da revisão sistemática da literatura.

\section{Apresentação dos resultados}

\subsection{Definições da gestão da demanda}

Para o Council of Supply Chain Management Professional (2009), a gestão da cadeia de suprimentos, também chamada de Supply Chain
Management (SCM), engloba o planejamento e a gestão de todas as atividades envolvidas com aquisição e suprimento, transformação e atividades de gerenciamento logístico. Isso inclui a coordenação e colaboração com membros da cadeia, que podem ser fornecedores, intermediários, provedores de serviços de terceira parte e clientes (COUNCIL..., 2009).

Mentzer et al. (2001) definem a gestão da cadeia de suprimentos como a coordenação sistêmica e estratégica das funções tradicionais e táticas de 
negócio dentro de uma empresa e entre empresas ao longo da cadeia de suprimentos, com o objetivo de melhorar os resultados de longo prazo da firma individualmente e da cadeia de suprimentos como um todo.

A gestão da cadeia de suprimentos para o Global Supply Chain Forum (GSCF) significa a integração dos processos-chave de negócio desde o usuário final até o fornecedor original que provê produtos, serviços e informações que agregam valor para os clientes e outros stakeholders (CROXTON et al., 2008; LAMBERT, 2004; LAMBERT; COOPER, 2000; LAMBERT; COOPER; PAGH, 1998). Nesta visão, o modelo de gestão da cadeia de suprimentos proposto pelo GSCF é baseado na integração de oito processos-chave de negócios das empresas, por meio de suas cadeias de suprimentos (LAMBERT; COOPER; PAGH, 1998).

Segundo Fawcett e Magnan (2002), apesar dos benefícios da integração e colaboração entre os membros da cadeia de suprimentos, poucas empresas alcançam o potencial da integração: cerca da metade das firmas pesquisadas estão trabalhando com a integração dentro da empresa, um terço das empresas foca seus esforços de integração com os fornecedores do primeiro nível da cadeia, havendo pouco esforço de integração entre os outros níveis.

Segundo Ballou (2006), isto ocorre provavelmente devido às dificuldades para alcançar colaboração efetiva e a algumas limitações como, por exemplo, resistência no compartilhamento de informações. Um fluxo de informação transparente na coordenação da cadeia de suprimentos pode ser a chave para reduzir as distorções da demanda (LEE; PADMANABHAN; WHANG, 1997; PAIK; BAGCHI, 2007).

Dentre os oito processos-chave da SCM propostos pelo GSCF, três são relacionados ao marketing: Gestão do Relacionamento com Clientes, Gestão de Serviço ao Cliente, Gestão da Demanda (JUTTNER; CHRISTOPHER; BAKER, 2007; LAMBERT, 2004).

Geralmente, a gestão da cadeia de suprimentos foca a eficiência dos processos relacionados a suprimentos (atendimento da demanda) e tende a ser orientada para custos, enquanto a gestão de marketing é mais preocupada com geração de receitas (criação de demanda), identificando as percepções de valor do consumidor e como estas podem ser transformadas em ofertas de produtos (JUTTNER; CHRISTOPHER; BAKER, 2007). Em tal ambiente, os processos de criação e atendimento da demanda não são integrados, marketing formula a estratégia (o que, onde e como vender) e a SCM executa. Isto implica que a missão da SCM é desenvolver capacidades e vantagens da cadeia de suprimentos conforme a estratégia de marketing. Porém, uma coordenação eficiente da gestão de marketing e da SCM pode resultar em maior vantagem competitiva (HILLETOFTH; ERICSSON; CHRISTOPHER, 2009).

Mentzer e Moon (2004) identificaram que a gestão da demanda, como também o próprio conceito de demanda, não são bem compreendidos pelos agentes da cadeia de suprimentos. Muitas empresas falharam e reconhecem que a coordenação na cadeia não é possível sem uma adequada compreensão da demanda.

Desta forma, o Quadro 7 apresenta as definições da gestão da demanda sob a ótica de diferentes autores.

Quadro 7. Definições da gestão da demanda.

\begin{tabular}{|c|c|}
\hline Autores & Definição de gestão da demanda \\
\hline Croxton et al. (2008) & $\begin{array}{l}\text { Processo da gestão da cadeia de suprimentos composto por } \\
\text { subprocessos operacionais e estratégicos com o objetivo de } \\
\text { determinar a previsão de vendas, sincronizá-la com a capacidade } \\
\text { produtiva da empresa e da cadeia, incorporar a estratégia da } \\
\text { organização e mapear as necessidades dos consumidores. }\end{array}$ \\
\hline $\begin{array}{l}\text { Hilletofth, Ericsson e Christopher } \\
\text { (2009); Hilletofth e Ericsson } \\
\text { (2007); Juttner, Christopher e } \\
\text { Baker (2007); Walters (2006); } \\
\text { Walters e Rainbird (2004) } \\
\end{array}$ & $\begin{array}{l}\text { Alinhamento dos processos de criação e atendimento da demanda } \\
\text { entre as funções internas da empresa e entre empresas da cadeia de } \\
\text { suprimentos. Explorando, assim, sinergias entre marketing e SCM } \\
\text { com o objetivo de obter vantagens competitivas. }\end{array}$ \\
\hline $\begin{array}{c}\text { Mentzer et al. (2007) } \\
\text { Mentzer e Moon (2005) }\end{array}$ & $\begin{array}{c}\text { Componente da gestão da cadeia de suprimentos. Criação de um } \\
\text { fluxo coordenado de demanda entre os membros da cadeia de } \\
\text { suprimentos e seus mercados. }\end{array}$ \\
\hline Vollmann et al. (2004) & $\begin{array}{l}\text { Interface-chave entre as atividades de produção da empresa, sistemas } \\
\text { de planejamento e controle e o mercado. Compreende atividades que } \\
\text { variam de previsão a converter os pedidos dos clientes em datas de } \\
\text { entrega e como um mecanismo de equilibrar oferta e demanda. }\end{array}$ \\
\hline Rainbird (2004) & $\begin{array}{c}\text { Compreensão das expectativas atuais e futuras dos clientes, } \\
\text { características do mercado, e das alternativas disponíveis de resposta } \\
\text { que são alcançadas por meio de processos operacionais. }\end{array}$ \\
\hline
\end{tabular}

Fonte: Croxton et al. (2008); Hilletofth, Ericsson e Christopher (2009); Hilletofth e Ericsson (2007); Juttner, Christopher e Baker (2007); Mentzer et al. (2007); Mentzer e Moon (2005); Rainbird (2004); Vollmann et al. (2004); Walters (2006); Walters e Rainbird (2004). 
Os conceitos e objetivos da gestão da demanda discutidos por diversos autores (CROXTON et al. 2008; HILLETOFTH; ERICSSON, 2007; HILLETOFTH; ERICSSON; CHRISTOPHER, 2009; JUTTNER; CHRISTOPHER; BAKER, 2007; LANGABEER; ROSE, 2002; MENTZER et al., 2007; MENTZER; MOON, 2005; RAINBIRD, 2004; VOLLMANN et al., 2004; WALTERS, 2006; WALTERS; RAINBIRD, 2004) pressupõem que a gestão da demanda não pode ser considerada um processo isolado ou uma atividade resumida à previsão de vendas. Os autores defendem um conceito mais abrangente que envolve a criação de sinergias entre as áreas operacionais e de marketing com o objetivo de compreender o mercado e desenvolver ações sincronizadas com a estratégia da empresa, capacidade produtiva e atendimento das necessidades do consumidor final. Faz-se necessário, portanto, compreender quais são os limites e as interfaces deste processo.

\subsection{Principais abordagens para gestão da demanda}

Para Hilletofth, Ericsson e Christopher (2009), existem três questões importantes que necessitam ser direcionadas adequadamente ao implementar a gestão da demanda com sucesso: criação da demanda, atendimento da demanda e coordenação destes dois processos. Tanto marketing quanto SCM direcionam estes processos conforme as exigências do mercado (HILLETOFTH; ERICSSON; CHRISTOPHER,
2009). Esta relação entre mercado, marketing e SCM é representada na Figura 1.

A abordagem da gestão da demanda deve incorporar todos os processos de criação e atendimento da demanda da empresa. Como pode ser visto na Figura 1, exemplos dos principais processos de criação de demanda são o planejamento estratégico de marketing, pesquisa de marketing, segmentação de mercado, desenvolvimento de produto, comercialização de produto, marketing e vendas, gestão do ciclo de vida do produto (HILLETOFTH; ERICSSON; CHRISTOPHER, 2009).

Os principais exemplos do processo de atendimento da demanda são o planejamento estratégico da cadeia de suprimentos, projeto da cadeia de suprimentos, operações da cadeia de suprimentos (HILLETOFTH; ERICSSON; CHRISTOPHER, 2009).

Para obter os benefícios da gestão da demanda, a empresa precisa coordenar os processos de criação e atendimento da demanda de forma efetiva e eficaz. Isto requer a colaboração entre marketing e SCM (HILLETOFTH; ERICSSON; CHRISTOPHER, 2009).

Juttner, Christopher e Baker (2007) propõem o modelo conceitual para a gestão da demanda na cadeia de suprimentos (Figura 2). Neste modelo, três temas integrativos foram identificados e estruturados num modelo conceitual da gestão da demanda: processo, configuração e interações sociais.

Os processos de demanda e suprimentos se sobrepõem, mas são diferentes. Os processos de demanda consistem em todos aqueles que são envolvidos os clientes e o mercado, com o objetivo

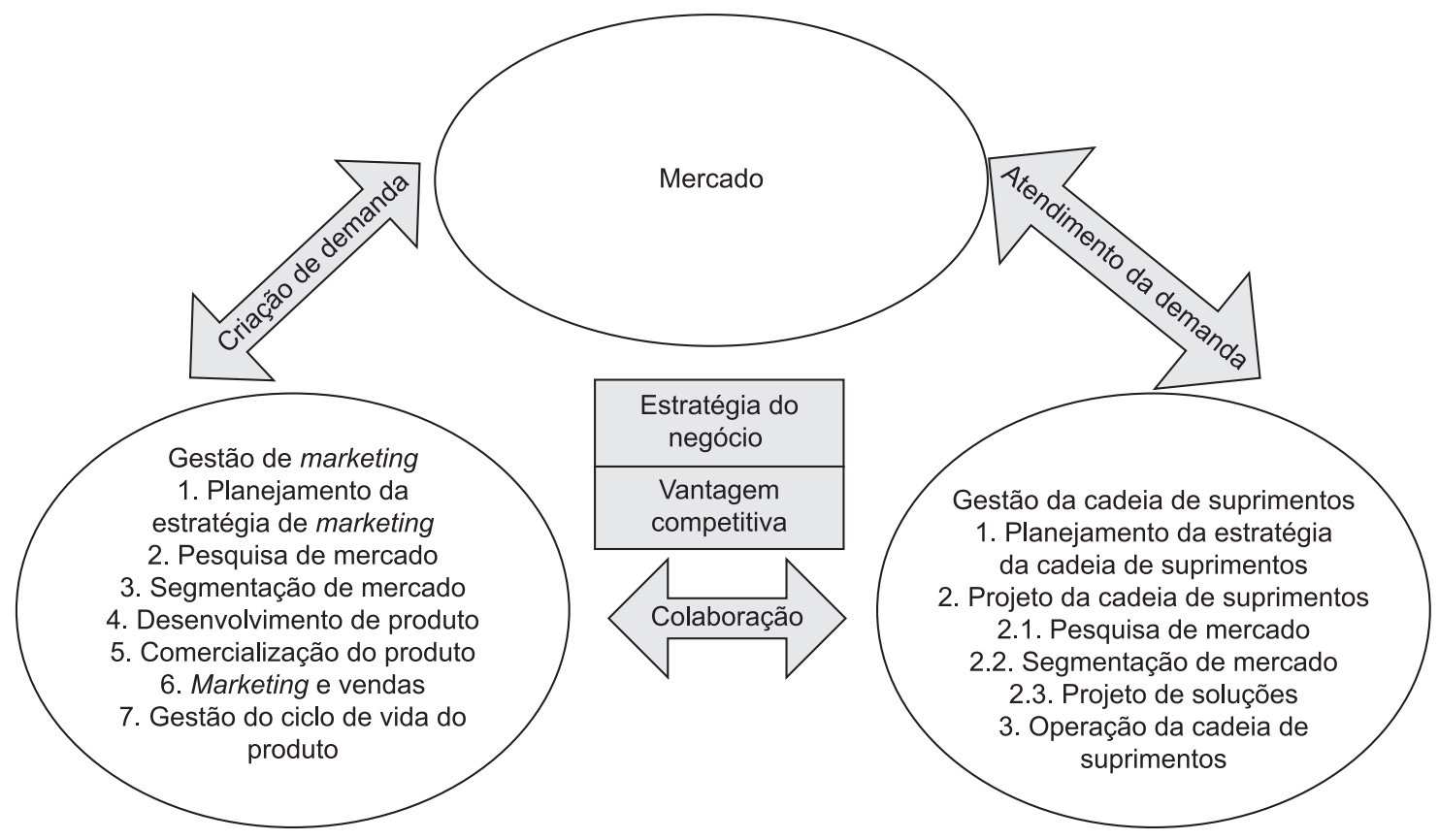

Figura 1. Estrutura da gestão da demanda. Fonte: Hilletofth, Ericsson e Christopher (2009, p. 1182). 
de responder à demanda do cliente por meio da criação de valor. Os processos de suprimentos envolvem tarefas necessárias para o atendimento da demanda. Assim, Juttner, Christopher e Baker (2007) defendem a necessidade da gestão da integração entre os processos de demanda e suprimentos.

A configuração se refere às decisões quanto ao número de segmentos de clientes que a empresa pode servir com cadeias de suprimentos diferenciadas, como também o aspecto estrutural do segmento do cliente, ou seja, as capacidades e processos requeridos da cadeia de suprimentos para atender a cada segmento (JUTTNER; CHRISTOPHER; BAKER, 2007).

Nas interações sociais, gestão de marketing deveria compartilhar com a gestão de suprimentos novos clientes, oportunidades de produtos, segmentos de clientes definidos, promoções planejadas, feedback das entregas. Da mesma forma, a gestão de suprimentos deveria compartilhar informações de lead time, capacidade e custos (estoque, armazém, transporte) com a gestão de marketing (JUTTNER; CHRISTOPHER; BAKER, 2007).

Assim, na gestão da demanda, marketing e suprimentos devem trabalhar juntos para desenvolver relacionamentos apropriados para diferentes clientes, desenvolver conjuntamente estratégias de priorização do cliente, processo acurado de informação ao consumidor, conciliar os requerimentos de valor com as capacidades operacionais. Os autores sugerem que a função da gestão de marketing nas empresas, no contexto da gestão da demanda, deve ser reavaliada, pois marketing precisa envolver o conhecimento de outros departamentos em suas tomadas de decisão e redefinir suas responsabilidades no processo integrado da demanda e de suprimentos (JUTTNER; CHRISTOPHER; BAKER, 2007).

Segundo Porter (1989, p. 31),

[...] a cadeia de valores desagrega uma empresa nas suas atividades de relevância estratégica para que se possa compreender o comportamento

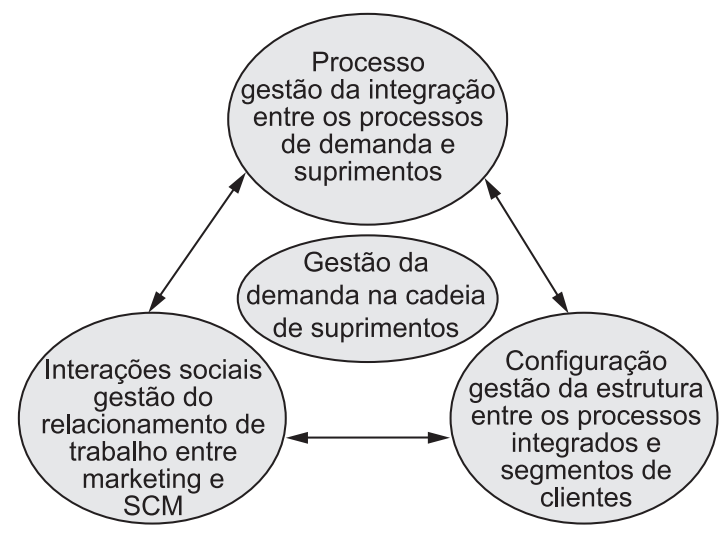

Figura 2. Modelo conceitual para a gestão da demanda na cadeia de suprimentos. Fonte: Juttner, Christopher e Baker (2007, p. 382). dos custos e as fontes existentes e potenciais de diferenciação.

Assim,

[...] toda empresa é uma reunião de atividades que são executadas para projetar, produzir, comercializar, entregar e sustentar seu produto. Todas estas atividades podem ser representadas, fazendo-se uso de uma cadeia de valores. (PORTER, 1989, p. 33).

Esper et al. (2009) classificam as atividades primárias propostas na estrutura de criação de valor de Porter (1989) em dois processos: focado na demanda (marketing, vendas, serviço ao cliente) e focado em suprimentos (logística interna, logística externa e operações). Os autores sugerem que o sucesso na gestão da cadeia de suprimentos para criar valor ao cliente requer uma integração extensiva entre os processos focados na demanda e os processos focados em suprimentos (Figura 3).

A integração dos processos de demanda e suprimentos inicia com o reconhecimento de que a organização possui um conjunto de estratégias e táticas relacionado à gestão da demanda e de suprimentos. A partir do acesso a este conjunto de estratégias e táticas da empresa, gerentes estudam as capacidades, restrições e oportunidades do ambiente externo para gerar informações da demanda e de suprimentos (ESPER et al., 2009).

A geração de conhecimento de suprimentos consiste em obter informações relevantes dos fornecedores (capacidades, desempenho, iniciativas estratégicas), sobre tecnologia, tendências da indústria, rede de relacionamentos, capacidade, nível de estoque, transporte, opções de armazenamento (ESPER et al., 2009).

O próximo passo é a disseminação da geração de conhecimento dos processos de demanda e suprimentos por meio de previsões. Assim, representantes destes processos, como também representantes externos à empresa podem compartilhar o conhecimento. Neste estágio, indivíduos responsáveis pela gestão da demanda devem compreender as dificuldades enfrentadas pela cadeia de suprimentos, e indivíduos responsáveis pela gestão de suprimentos devem entender as dificuldades enfrentadas no mercado. Isto permite uma estratégia de tomada de decisão mais integrada e efetiva (ESPER et al., 2009).

O último elemento da estrutura proposta por Esper et al. (2009) é a aplicação do conhecimento que toma forma por meio dos planos de demanda e de operações. Nos planos de demanda, são aplicados os "4 Ps" (produto, preço, praça, promoção) de marketing para a gestão ativa da demanda. O plano operacional reflete a compreensão das oportunidades de demanda: onde é possível aumentá-la, onde é desejável diminuí-la. Assim, o plano operacional 


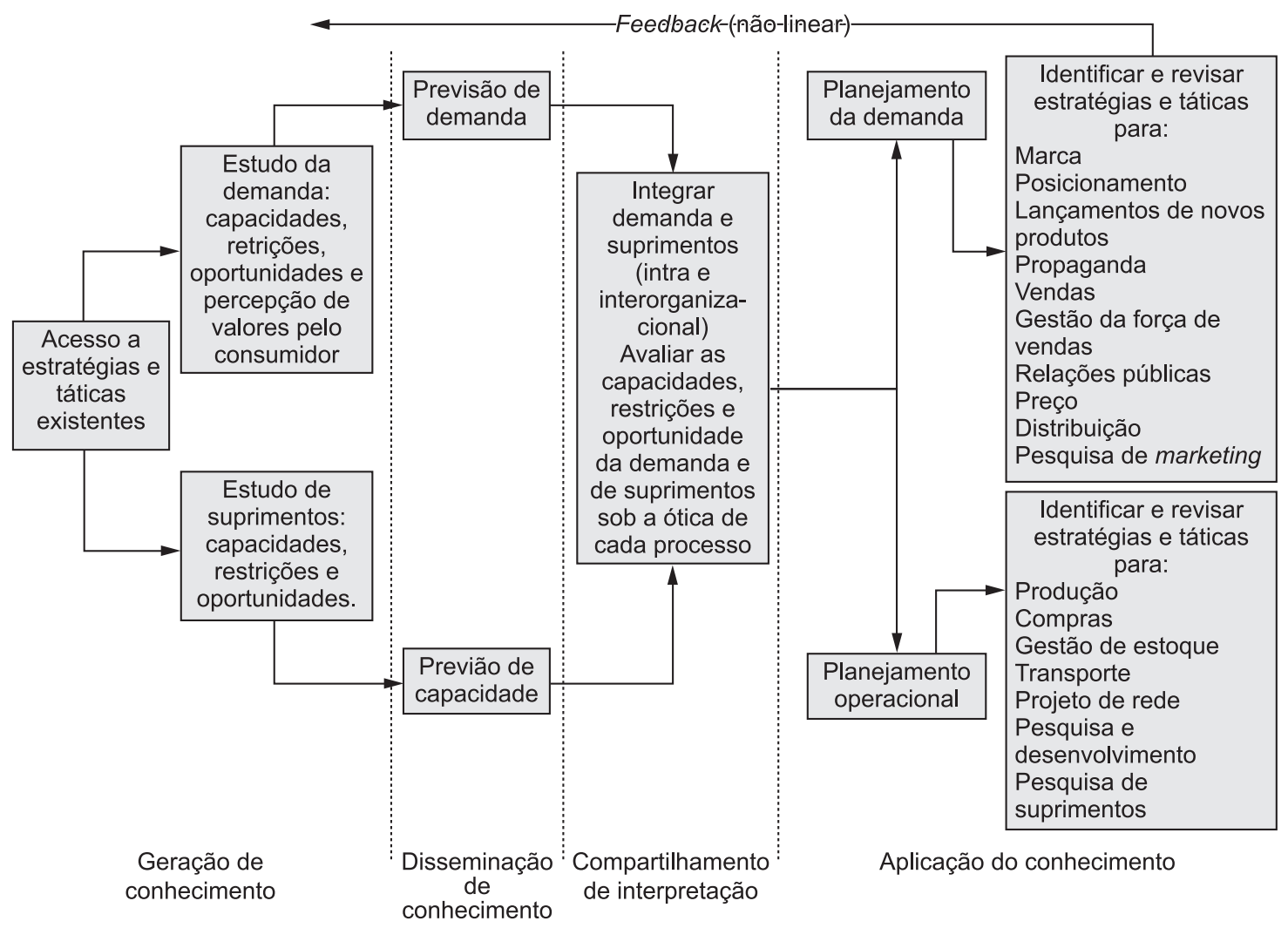

Figura 3. Criação de valor ao cliente por meio da integração da demanda e suprimentos. Fonte: Esper et al. (2009, p. 4).

envolve direções estratégicas de como efetivamente executar a produção, compras, estoque e distribuição. Além disso, inclui abordagens para gerir fornecedores para o suporte efetivo das iniciativas planejadas e esperadas de marketing.

Segundo Mentzer et al. (2007), a gestão da demanda é a criação de um fluxo coordenado de demanda entre os membros da cadeia de suprimentos e seus mercados. Os autores ressaltam alguns pontos que estão implicados nesta definição. O primeiro deles refere-se à função tradicional da área de marketing que estabelece a demanda de vários produtos, mas geralmente não compartilha o plano de demanda com outras funções internas à empresa, muito menos com outras empresas na cadeia de suprimentos. Além disso, a gestão da demanda implica a análise da contribuição de vários produtos e clientes, enfatizando a demanda para os mais rentáveis e diminuindo a demanda, pela redução dos esforços de marketing, para os não lucrativos. Por último, um aspecto da gestão da demanda é a gestão do relacionamento na cadeia de suprimentos que envolve todos os parceiros com objetivo de alcançar um melhor desempenho na cadeia.

Mentzer e Moon (2005) classificam a demanda em independente, derivada e dependente. A primeira representa a quantidade demandada pelo consumidor final; a segunda, a demanda que é derivada do que outras empresas na cadeia de suprimentos fazem para atender à demanda de seus clientes imediatos; e, por fim, a demanda dependente é a demanda por componentes do produto.

Assim, a gestão da demanda é um componente da gestão da cadeia de suprimentos, englobando as funções tradicionais do marketing, como a coordenação das atividades de marketing com outras funções na empresa e na própria cadeia de suprimentos. Também abrange o planejamento da demanda que é o fluxo coordenado da demanda derivada e dependente pelas empresas na cadeia de suprimentos. Por sua vez, o planejamento da demanda inclui a gestão de previsão de demanda que se preocupa com a demanda independente que ocorre em qualquer cadeia de suprimentos (MENTZER; MOON, 2005). Esta definição é ilustrada na Figura 4.

Na Figura 5, Croxton et al. (2008) propõem o modelo de gestão da demanda. A estrutura é baseada na literatura e em entrevistas em profundidade com gerentes de diversas indústrias. Este modelo foi validado em quatro sessões de trabalho com membros do Global Supply Chain Forum num período de 18 meses.

A estrutura do modelo permite que a gestão da demanda seja compreendida a partir de todas as suas interfaces, oferecendo, assim, uma visão integrada de seu relacionamento com outros processos, funções organizacionais e elos-chave da cadeia de suprimentos. 


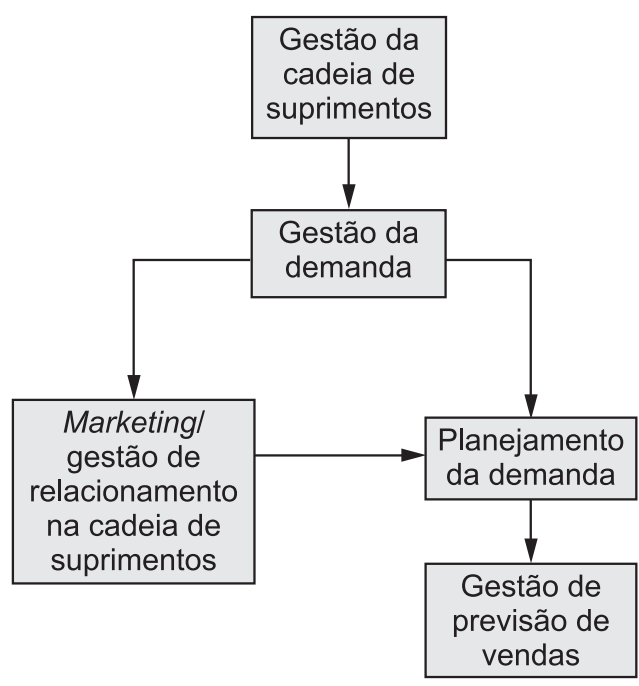

Figura 4. Gestão da demanda na cadeia de suprimentos. Fonte: Mentzer e Moon (2005, p. 8).
Nesta perspectiva, o modelo divide a gestão da demanda em dois conjuntos: subprocessos estratégicos e subprocessos operacionais. A Figura 5 mostra as interfaces entre cada subprocesso e os demais sete processos propostos pelo GSCF. Estas interfaces podem significar transferência de dados que outros processos requerem ou pode envolver o compartilhamento de informações ou ideias com outros times de processo (CROXTON et al., 2008).

Vollmann et al. (2004) e Croxton et al. (2008) propõem uma visão multifuncional para o processo de gestão da demanda ao sugerir um time composto por integrantes de diversos níveis e setores da organização, bem como representantes de elos-chave da cadeia de suprimentos. Em função do caráter estratégico, o time deve ser composto pelos gerentes de várias funções incluindo marketing, finanças, produção, compras e logística. Eventualmente, colaboradores de outras áreas da empresa e representantes de fornecedores e clientes estratégicos devem participar do time.

Gestão da demanda

Sub-processos estratégicos

Interfaces processuais

Sub-processos operacionais

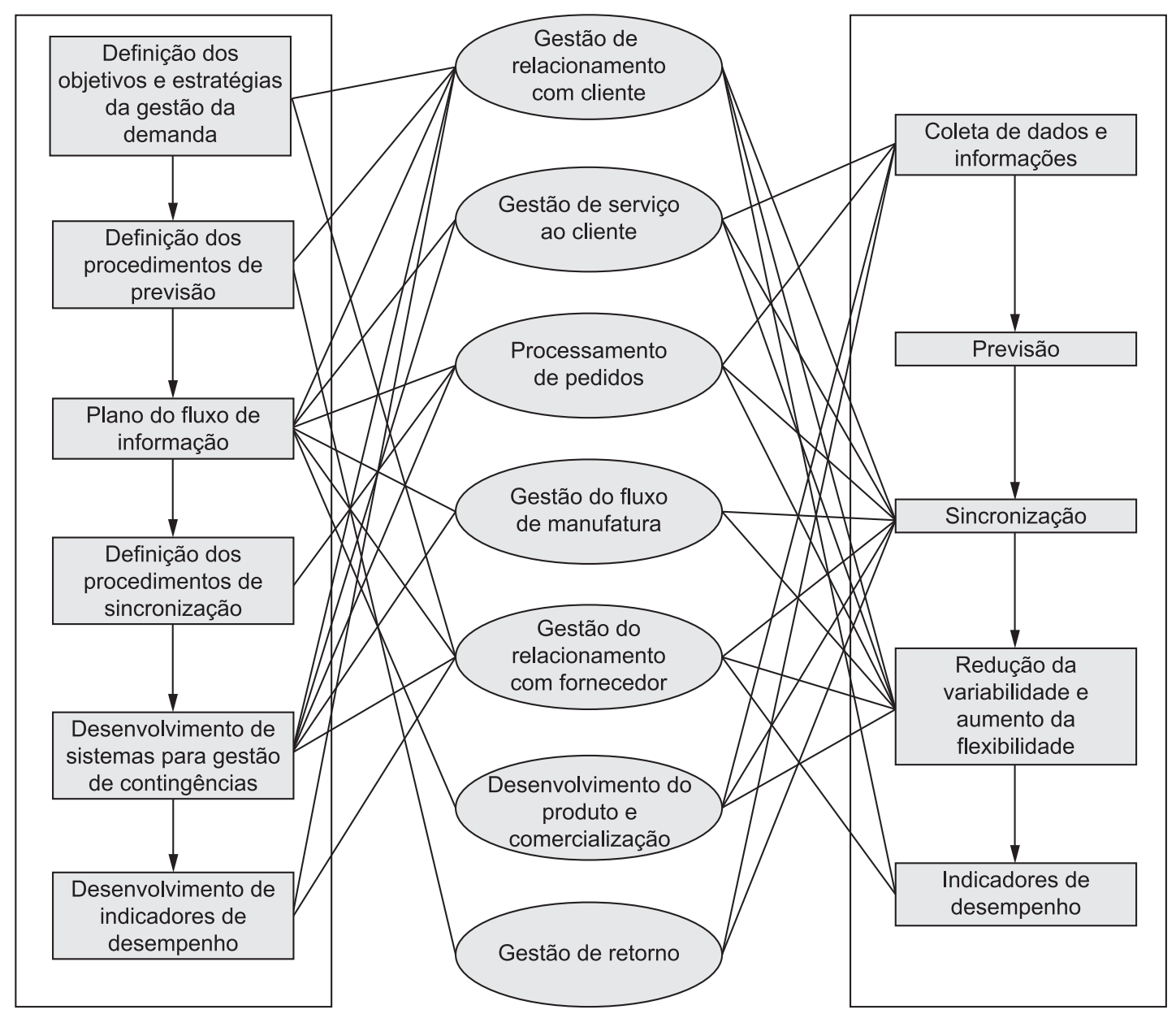

Figura 5. Modelo de Gestão da Demanda. Fonte: Croxton et al. (2008, p. 89). 
Este time é responsável pelo desenvolvimento de procedimentos no nível estratégico e por garantir a implementação deles. No plano operacional, possui a responsabilidade de cuidar do andamento diário do processo (CROXTON et al., 2008).

Na visão de Croxton et al. (2008), o time de processo deve ter uma ampla compreensão da estratégia da organização, dos consumidores e das necessidades destes, das capacidades da manufatura e da rede da cadeia de suprimentos. Em termos estratégicos, o processo pode ter duas orientações: aumentar a flexibilidade do sistema produtivo para atender à demanda ou aperfeiçoar os métodos para redução dos erros de previsão.

É responsabilidade do time de execução definir procedimentos para elaboração da previsão. Croxton et al. (2008) destacam a necessidade de definir o enfoque da previsão. As decisões que cercam esta definição consistem em determinar o nível de detalhamento, abrangência da previsão e identificação das fontes de informação.

Mentzer et al. (2007) definem previsão de vendas como a projeção para o futuro da demanda esperada, dado um conjunto de condições ambientais. Ela deve ser distinguida de planos que são um conjunto de ações gerenciais a serem tomadas para alcançar ou exceder as previsões de vendas. Os planos de vendas a serem alcançados devem ser baseados na previsão de vendas. O objetivo da previsão de vendas é a acuracidade, enquanto que o objetivo dos planos é alcançar a previsão de demanda eficiente e eficazmente.

O processo de formulação da previsão pode receber importantes entradas de diversas áreas da empresa. As previsões são comunicadas internamente para outros times de processo que são afetados por elas. Além disso, a empresa precisa determinar que dados serão compartilhados com outros membros da cadeia de suprimentos (CROXTON et al., 2008).

Para Mentzer et al. (2007), empresas que são efetivas na previsão de vendas e na elaboração do plano de negócios iniciam com o processo de previsão de vendas. Dadas as condições econômicas e competitivas e planos iniciais de marketing, vendas, produção e logística, uma projeção para a demanda esperada no futuro é feita. Desta base, o plano de negócios pode ser desenvolvido.

Muitos gerentes questionam a necessidade de uma previsão de vendas já que as metas de vendas podem ser alcançadas ou até mesmo excedidas. Mentzer et al. (2007) consideram que antes de qualquer plano é necessário uma previsão. Os executivos devem iniciar o processo com uma análise do mercado e das condições ambientais, definindo as vendas esperadas conforme esta análise. Portanto, o plano determina os esforços da equipe de marketing e vendas para alcançar e exceder as projeções com rentabilidade.
Assim, se o plano de negócios resultante não estiver alinhado com as necessidades e objetivos financeiros da empresa, retorna-se na previsão de vendas e examina-se que esforços adicionais de marketing ou vendas podem ser realizados para aumentar a previsão da demanda e quais esforços adicionais das áreas de produção ou logística podem ser realizados para aumentar a capacidade para o nível necessário para alcançar o plano de negócios. Garantindo, portanto, um plano de negócios baseado nas realidades financeiras e de mercado que a empresa enfrenta, nas capacidades logísticas e de produção, e da cadeia de suprimentos (MENTZER et al., 2007).

Alguns autores (AGHAZADEH, 2004; KATZ; PAGELL; BLOODGOOD, 2003; TAYLOR; FEARNE, 2006) destacam a importância da acuracidade da previsão de vendas para a melhoria do desempenho da cadeia de suprimentos.

Para finalizar as abordagens para a gestão da demanda, constata-se que as empresas podem implantar diferentes níveis das iniciativas de S\&OP (Planejamento de Vendas e Operações) (GRIMSON; PYKE, 2007; LAPIDE, 2005) e de CPFR (Planejamento, Previsão e Reposição Colaborativos) (DANESE, 2007; LARSEN; THERNOE; ANDRESEN, 2003; SEIFERT, 2003) na gestão da demanda. Verifica-se na literatura a utilização de termos S\&OP, CPFR e Planejamento Integrado de Negócios (IBP) para designar processos e atividades similares, mas que são diferentes. O S\&OP é uma integração interfuncional que visa conciliar os planos de marketing e de operações na organização (ASSOCIATION..., 2009; CROXTON et al., 2008; TROQUE, 2003; VOLUNTARY..., 2010; WALLACE, 2004) e que pode evoluir para uma integração interempresas (GRIMSON; PYKE, 2007; LAPIDE 2005).

O CPFR é uma iniciativa entre os agentes da cadeia de suprimentos com o objetivo de melhorar o relacionamento por meio do planejamento e gerenciamento conjunto dos processos e compartilhamento de informações (SEIFERT, 2003). Assim, no CPFR, o fornecedor é envolvido no planejamento da demanda, porém, conforme Voluntary Interindustry Commerce Standards (2010), geralmente os planos de vendas não incluem iniciativas futuras como campanhas de marketing, promoções e lançamento de produtos.

Voluntary Interindustry Commerce Standards (2010), então, propõe combinar os modelos S\&OP e CPFR para desenvolver o Planejamento Integrado de Negócios (IBP) em que as atividades de S\&OP (alinhamento interno, ciclo de revisão mensal, horizonte de planejamento, envolvimento de executivos com poder de decisão, detalhamento do plano de vendas e de marketing) são incorporadas ao CPFR. 
Assim, com base na revisão teórica, a abordagem conceitual para uma efetiva gestão da demanda é proposta no próximo tópico.

\subsubsection{Abordagem conceitual para uma efetiva gestão da demanda}

A revisão da literatura possibilitou identificar duas abordagens da gestão da demanda que podem ser resumidas no Quadro 8. Dentre estas abordagens, destacam-se estudiosos de marketing que defendem a necessidade da integração da gestão de marketing e suprimentos (ESPER et al., 2009; HILLETOFTH; ERICSSON; CHRISTOPHER, 2009; JUTTNER; CHRISTOPHER; BAKER, 2007; VOLUNTARY..., 2010) e estudiosos da gestão da cadeia de suprimentos que definem a gestão da demanda como um processo ou componente da SCM (CROXTON et al., 2008; MENTZER; MOON, 2005).

Esta pesquisa foca a gestão da demanda em cadeias de suprimentos. Considera, portanto, a abordagem de gestão da demanda proposta por Croxton et al. (2008);

Quadro 8. Abordagens da gestão da demanda.

\begin{tabular}{|c|c|c|}
\hline $\begin{array}{l}\text { Abordagem } \\
\text { da gestão da } \\
\text { demanda }\end{array}$ & Autores & Descrição da abordagem da gestão da demanda \\
\hline \multirow[t]{3}{*}{$\begin{array}{l}\text { Gestão da } \\
\text { demanda } \\
\text { como a } \\
\text { integração } \\
\text { da gestão de } \\
\text { marketing e } \\
\text { suprimentos }\end{array}$} & Esper et al. (2009) & $\begin{array}{l}\text { Sugerem que o sucesso na gestão da cadeia de suprimentos para criar } \\
\text { valor ao cliente requer uma integração extensiva entre os processos } \\
\text { focados na demanda e os processos focados em suprimentos. Os } \\
\text { gerentes devem estudar as capacidades, restrições e oportunidades } \\
\text { do ambiente externo para gerar informações da demanda e de } \\
\text { suprimentos. }\end{array}$ \\
\hline & $\begin{array}{c}\text { Juttner, Christopher e } \\
\text { Baker (2007) } \\
\text { Hilletofth, Ericsson e } \\
\text { Christopher (2009) }\end{array}$ & $\begin{array}{l}\text { A gestão da demanda é composta pelos processos de criação da } \\
\text { demanda e atendimento da demanda, sendo necessário coordenar } \\
\text { estes processos por meio da colaboração das duas áreas. Assim, } \\
\text { marketing e suprimentos devem trabalhar juntos para desenvolver } \\
\text { relacionamentos apropriados para diferentes clientes, desenvolver } \\
\text { conjuntamente estratégias de priorização do cliente, processo acurado } \\
\text { de informação ao consumidor, conciliar os requerimentos de valor com } \\
\text { as capacidades operacionais. }\end{array}$ \\
\hline & $\begin{array}{l}\text { Voluntary Interindustry } \\
\text { Commerce Standards } \\
\text { (2010) }\end{array}$ & $\begin{array}{c}\text { A gestão da demanda é composta pela integração do Planejamento de } \\
\text { Vendas \& Operações (S\&OP) e do Planejamento, Previsão e Reposição } \\
\text { Colaborativos (CPFR). }\end{array}$ \\
\hline \multirow[t]{2}{*}{$\begin{array}{l}\text { Gestão da } \\
\text { demanda } \\
\text { como um } \\
\text { processo ou } \\
\text { componente } \\
\text { da SCM }\end{array}$} & Croxton et al. (2008) & $\begin{array}{l}\text { Gestão da demanda como um processo da gestão da cadeia de } \\
\text { suprimentos, enfatizando a necessidade de implantar subprocessos } \\
\text { operacionais e estratégicos buscando entender, influenciar e gerenciar } \\
\text { a demanda dos consumidores, alcançando resposta rápida em toda a } \\
\text { cadeia de suprimentos. Propõem a criação de um time multifuncional } \\
\text { composto por integrantes de diversos níveis e setores da organização } \\
\text { (marketing, finanças, produção, compras e logística), bem como } \\
\text { representantes estratégicos da cadeia de suprimentos (fornecedores } \\
\text { e clientes). Assim, este time é responsável pelo desenvolvimento de } \\
\text { procedimentos no nível estratégico e por garantir a implementação } \\
\text { deles. No plano operacional, possui a responsabilidade de cuidar do } \\
\text { andamento diário do processo. }\end{array}$ \\
\hline & $\begin{array}{c}\text { Mentzer e Moon } \\
(2005)\end{array}$ & $\begin{array}{l}\text { Gestão da demanda como a criação de um fluxo coordenado de } \\
\text { demanda entre os membros da cadeia de suprimentos e seus mercados. } \\
\text { Consideram a gestão da demanda como um componente da gestão } \\
\text { da cadeia de suprimentos, englobando a gestão de marketing e a } \\
\text { sua coordenação com os agentes da cadeia (internos e externos) e } \\
\text { o planejamento da demanda. Este, por sua vez, inclui a gestão de } \\
\text { previsão de demanda que se preocupada com a quantidade demandada } \\
\text { pelo consumidor final. } \\
\text { Consideram que antes de qualquer plano é necessário uma previsão, cujo } \\
\text { processo deve ser iniciado com uma análise do mercado e das condições } \\
\text { ambientais, definindo as vendas esperadas conforme esta análise. }\end{array}$ \\
\hline
\end{tabular}

Fonte: Croxton et al. (2008); Esper et al. (2009); Hilletofth, Ericsson e Christopher (2009); Juttner, Christopher e Baker (2007); Mentzer e Moon (2005); Voluntary Interindustry Commerce Standards (2010). 
Mentzer e Moon (2005). O direcionamento neste estudo para esta abordagem não exclui a outra, pois a proposta da gestão da demanda como a integração da gestão de marketing e suprimentos contribui para esta pesquisa como fator importante para a sincronização da demanda. Esta é detalhada por Croxton et al. (2008) como um subprocesso estratégico (definição dos procedimentos de sincronização) e operacional (sincronização) do processo de gestão da demanda.

Além disso, a influência das atividades de marketing na gestão da cadeia de suprimentos, e vice-versa, precisa ser compreendida e coordenada. Preço do produto, estratégias de promoção, como também os esforços para melhorar e ampliar o mix de produtos influenciam os tempos de entrega e os custos da cadeia de suprimentos, ao mesmo tempo que os custos da cadeia de suprimentos impactam a rentabilidade do produto.

$\mathrm{Na}$ gestão da demanda, a gestão de marketing e a $S C M$ trabalham juntas para desenvolver relacionamentos apropriados para diferentes clientes, estratégias de priorização do cliente e processo acurado de informação ao consumidor. Como também desenvolvem ações conjuntas para conciliar os requerimentos de valor com as capacidades operacionais.

Com o objetivo de conciliar os interesses da gestão de marketing e da gestão da cadeia de suprimentos, este artigo propõe uma abordagem conceitual para alcançar uma efetiva gestão da demanda, representada na Figura 6.

Assim, o primeiro passo consiste na compreensão do mercado (CROXTON et al., 2008; ESTER et al., 2009; HILLETOFTH; ERICSSON; CHRISTOPHER, 2009; JUTTNER; CHRISTOPHER; BAKER, 2007; MENTZER; MOON, 2004; RAINBIRD, 2004) por meio da análise das capacidades, restrições, oportunidades dos ambientes interno e externo à empresa. Este conhecimento envolve o compartilhamento de informações estratégicas e operacionais entre as empresas para conhecer as dificuldades e potencialidades do parceiro (VIEIRA; YOSHIZAKI; HO, 2009) e gerar informações de previsões de demanda e suprimentos (informações de capacidade, iniciativas, estratégias dos fornecedores, tecnologia, tendências do setor, nível de estoque, transporte, opções de armazenamento) (ESPER et al., 2010). Além disso, ter acesso à intenção estratégica do parceiro permite o conhecimento do objetivo de crescimento, obtenção de participação de mercado, melhoria dos serviços oferecidos (MIN et al., 2005). Desta forma, o conhecimento do mercado ditará as diretrizes e práticas estratégicas e operacionais da organização.

O processo de gestão da demanda envolve um time multifuncional composto por integrantes de diversos níveis e setores da organização, bem como representantes estratégicos da cadeia de suprimentos (fornecedores e clientes) (CROXTON et al., 2008; HILLETOFTH; ERICSSON; CHRISTOPHER, 2009; JUTTNER; CHRISTOPHER; BAKER, 2007; MENTZER et al., 2007; VOLLMANN et al., 2004). Estes representantes serão responsáveis pelo desenvolvimento conjunto das previsões de vendas e do plano de negócio. Cada área terá suas ações específicas para serem executadas e o acompanhamento do plano de negócios deverá ser individual e em conjunto por meio de reuniões periódicas das equipes multifuncionais.

Estas equipes multifuncionais devem ter uma ampla compreensão do mercado, das diretrizes e práticas estratégicas e operacionais da organização (CROXTON et al., 2008; ESTER et al., 2009; HILLETOFTH; ERICSSON; CHRISTOPHER, 2009; MENTZER et al., 2007).

Para o desenvolvimento conjunto das previsões de vendas, bem como a elaboração, execução e acompanhamento do plano de negócio pelas equipes multifuncionais, os agentes internos e externos da cadeia precisam ter uma orientação para a cadeia de suprimentos (CROXTON et al., 2008; HILLETOFTH; ERICSSON, 2007; HILLETOFTH; ERICSSON;

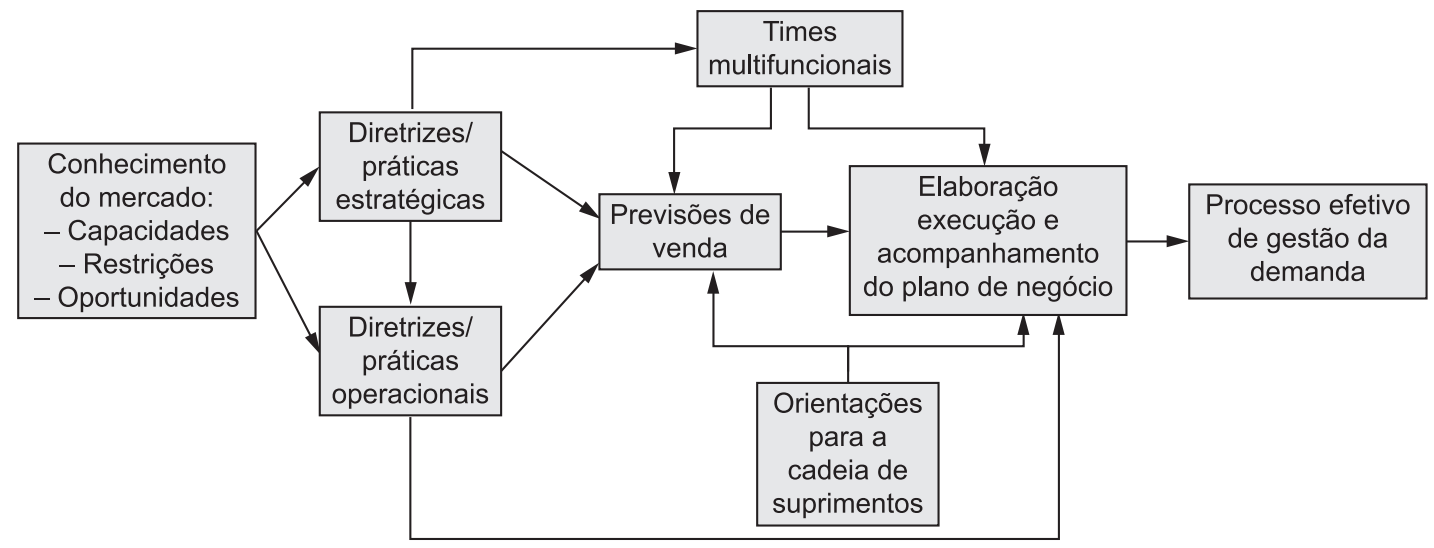

Figura 6. Estrutura conceitual para um processo efetivo de gestão da demanda. Fonte: Elaborado pelas autoras. 
CHRISTOPHER, 2009; JUTTNER; CHRISTOPHER; BAKER, 2007; MENTZER et al., 2001, 2007; MENTZER; MOON, 2005; VOLLMANN et al., 2004).

Segundo Mentzer et al. (2001), a orientação para a cadeia de suprimentos é um prerrequisito para a gestão da cadeia de suprimentos que consiste no desenvolvimento de esforços colaborativos intra e interempresas. Estes esforços representam os elementos da colaboração conforme Chen, Daugherty e Roath (2009); Fawcett, Magnan e McCarter (2008); Holweg et al. (2005); Horvath (2001); Mentzer, Fonghin e Golicic (2000); Min et al. (2005); Sabath e Fontanella (2002); Simatupang e Sridharan (2002, 2004); Stank, Keller e Daugherty (2001); Vieira, Yoshizaki e Ho (2009): compartilhamento de informações; planejamento e execução de ações conjuntas; compartilhamento de riscos, custos e ganhos; desenvolvimento de relacionamento interno e externo à organização; investimentos financeiros e não financeiros; definição e acompanhamento de indicadores de desempenho

Min et al. (2005) citam como uma das consequências da colaboração na cadeia de suprimentos, à medida que o relacionamento entre os parceiros melhora, o desenvolvimento de um plano de negócios conjunto que será executado pelas equipes interfuncionais de cada empresa. No contexto da gestão da demanda, os autores conceituam "plano" como um conjunto de ações gerenciais específicas a serem tomadas para alcançar ou exceder as previsões de vendas. Diante das condições econômicas, da concorrência, dos planos de Marketing, Vendas, Produção e Logística, a projeção da demanda futura é realizada. Desta base, o plano de negócios é desenvolvido e este processo é iterativo, pois, se o plano de negócios resultante não estiver alinhado com as necessidades e objetivos financeiros da empresa, retorna-se à previsão de vendas e se examina que esforços adicionais podem ser realizados para alcançar o plano de negócios. Garantindo, portanto, um plano baseado nas realidades financeiras e de mercado que a empresa enfrenta, nas capacidades logísticas e de produção, e da cadeia de suprimentos.

No CPFR, as empresas parceiras irão desenvolver um plano de negócio conjunto para identificar os eventos significantes que afetam o fornecimento e a demanda, estabelecendo as previsões de vendas e de ressuprimento (VOLUNTARY..., 2004). O S\&OP envolve a integração dos planos de marketing com a gestão da cadeia de suprimentos para dar suporte ao processo de planejamento anual de negócios. Este processo requer um plano de demanda, suprimentos e finanças sincronizado com a identificação dos riscos, oportunidades, planos de ação para solucionar os problemas (WALLACE, 2004). Voluntary Interindustry Commerce Standards (2010) propõe desenvolver um plano de negócio integrado em que atividades do S\&OP, como, por exemplo, alinhamento interno, ciclo de revisão mensal, horizonte de planejamento, envolvimento de executivos com poder de decisão, detalhamento do plano de vendas e de marketing, são incorporadas ao CPFR.

Segundo Esper et al. (2010), a aplicação do conhecimento dos ambientes interno e externos e das previsões de demanda e de capacidade toma forma por meio dos planos de demanda (4Ps de marketing: preço, praça, promoção e produto) e de operações (produção, estoque, compras e distribuição). Assim, na gestão da demanda, a gestão de marketing e a gestão da cadeia de suprimentos trabalham juntas para desenvolver relacionamentos apropriados para diferentes clientes, estratégias de priorização do cliente e processo acurado de informação ao consumidor. Como também desenvolvem ações conjuntas para conciliar os requerimentos de valor com as capacidades operacionais.

Para Croxton et al. (2008), a execução de um plano único tem por objetivo equilibrar as necessidades e os custos da Manufatura, Logística, Vendas e fornecedores para atender a uma demanda antecipada. Desta forma, constata-se a utilização dos termos "plano de negócio conjunto" (BARRATT; OLIVEIRA, 2001; MIN et al., 2005; VOLUNTARY..., 2004), "plano de negócio integrado" (VOLUNTARY..., 2010), "plano de negócio" (MENTZER et al., 2007), "plano de demanda, suprimentos e finanças" (WALLACE, 2004), "plano de demanda e operações" (ESPER et al., 2010), "plano único" (CROXTON et al., 2008) para designar um conjunto de ações desenvolvidas por parceiros na cadeia de suprimentos. Estas ações englobam a sincronização da gestão de marketing e de operações para melhor atender à demanda; as ações devem estar alinhadas com o direcionamento estratégico das empresas.

Por fim, o processo de gestão da demanda deve ser formalizado detalhando as métricas de desempenho (MIN et al., 2005) que envolvem direcionamentos específicos em custos, produtividade e metas de ganhos. No processo de gestão da demanda, as equipes multifuncionais desenvolvem uma estrutura de indicadores para medir e monitorar o processo e estabelecem os objetivos para a melhoria de desempenho (CROXTON et al., 2008).

Baseada nesta discussão da literatura, a Figura 6 mostra a estrutura conceitual para a implantação de um processo efetivo de gestão da demanda.

\section{Conclusões}

As mudanças de ordem econômica como, por exemplo, a globalização, impulsionaram o desenvolvimento do mercado, exigindo das empresas variedade de produtos, customização e melhores níveis de serviço. Neste novo contexto, a gestão da demanda emerge no campo de conhecimento da gestão 
da cadeia de suprimentos e de marketing buscando balancear e alinhar estrategicamente a demanda com a capacidade operacional ao longo da cadeia de suprimentos por meio da rápida e adequada integração das necessidades originadas do mercado na direção dos fornecedores. Estas mudanças geraram novos desafios para as organizações, fazendo com que estas identifiquem as percepções de valor do consumidor e como as percepções podem ser transformadas em ofertas de produtos.

A gestão da demanda deve equilibrar as necessidades dos clientes com as capacidades da empresa, reduzindo incertezas e fornecendo fluxos eficientes na cadeia de suprimentos. Portanto, a gestão da demanda é um componente importante para o sucesso da gestão da cadeia de suprimentos. Uma implementação bem conduzida do processo pode melhorar o nível de serviço prestado ao cliente e gerar benefícios substanciais para os resultados financeiros da empresa como, por exemplo, a redução dos níveis de estoque, melhoria da utilização dos ativos e melhoria na disponibilidade do produto.

Neste trabalho, foi proposta uma abordagem conceitual para a efetiva gestão da demanda sob a perspectiva da gestão da cadeia de suprimentos. Com isso, espera-se estar contribuindo para uma melhor compreensão e visão mais ampla da gestão da demanda como um processo integrado que aponta caminhos a serem adotados pelas organizações para a superação dos desafios atuais de conciliar as necessidades dos clientes e as capacidades da cadeia de suprimentos. Além disso, contribui para a literatura, pois há pouca informação disponível sobre a gestão da demanda em cadeias de suprimentos e a aplicação da gestão da demanda é ainda muito recente, necessitando de mais pesquisas que abordem o tema.

\section{Referências}

ACHROL, R. Chances in the theory of inter-organizational relations in marketing: toward a network paradigm. Journal of the Academy of Marketing Science, v. 25, n. 1, 1997. http://dx.doi.org/10.1007/BF02894509

ACHROL, R. Evolution of the marketing organization: new forms for dynamic environments. Journal of Marketing, v. 55, n. 4, 1991. http://dx.doi.org/10.2307/1251958

ACHROL, R.; KOTLHER, P. Marketing in the network economy. Journal of Marketing, v. 63, special issue, 1999.

ADEBANJO, D. Understanding demand management challenges in intermediary food trading: a case study. Supply Chain Management, v. 14, n. 3, 2009. http:// dx.doi.org/10.1108/13598540910954566

AGHAZADEH, S. Improving logistics operations across the food industry supply chain. International Journal of Contemporary Hospitality Management, v. 16, n. 4, 2004. http://dx.doi.org/10.1108/09596110410537423
ALVARADO, U.; KOTZAB, H. Supply chain management: the integration of logistics in marketing. Industrial Marketing Management, v. 30, n. 2, 2001. http:// dx.doi.org/10.1016/S0019-8501(00)00142-5

ASSOCIATION FOR OPERATIONS MANAGEMENT - APICS.Sales and Operations Planning: the secret to world class supply chain. APICS, 2009 Apicsdinner meeting. Disponível em: <http://www.apics-fraservalley. org/uploads/files/Year0809/april2009PDM.pdf>. Acesso em: 29 dez. 2010.

BALLOU, R. H. The evolution and future of logistics and supply chain management. Produção, v. 16, n. 3, 2006.

BARRATT, M.; OLIVEIRA, A. Exploring the experiences of collaborative planning iniciatives. International Journal of Physical Distribution \& Logistics Management, v. 31, n. 4, 2001. http://dx.doi. org/10.1108/09600030110394932

BECHTEL, C.; JAYARAM, J. Supply chain management: a strategic perspective, International Journal of Logistics Management, v. 8, n. 1, 1997. http://dx.doi. org/10.1108/09574099710805565

CHEN, H.; DAUGHERTY, P. J.; ROATH, A. S. Defining and operationalizing supply chain process integration. Journal of Business Logistics, v. 30, n. 1, 2009. http:// dx.doi.org/10.1002/j.2158-1592.2009.tb00099.x

COOPER, M. C., LAMBERT, D. M.; PAGH, J. D. Supply Chain Management: more than a new name for logistics. International Journal of Logistics Management, v. 8, n. 1, 1997. http://dx.doi.org/10.1108/09574099710805556

COUNCIL OF SUPPLY CHAIN MANAGEMENT PROFESSIONAL - CSCMP. Supply chain management Definitions. Disponível em: <http://cscmp.org/ aboutcscmp/definitions.asp? $\mathrm{XX}=1>$ Acesso em: 10 abr. 2009.

CROXTON, K. L. et al. The Demand Management Process. In: LAMBERT, D. M. Supply Chain Management: Processes, Partnerships, Performance. Florida: Supply Chain Management Institute, 2008. p. 87-104.

DANESE, P. Designing CPFR collaborations: insights from seven case studies. International Journal of Operations \& Production Management, v. 27, n. 2, 2007, p. 181-204. http://dx.doi.org/10.1108/01443570710720612

DENYER, D.; TRANFIELD, D. Producing a systematic review.In BUCHANAN, D.A.; BRYMAN, A. (Eds.).The sage handbook of Organizational research Methods. London: Sage Publications, 2009, p. 671-689.

ESPER, T. L. et al. Demand and supply integration: a conceptual framework of value creation through knowledge management. Academy of Marketing Science, 2009.

FAWCETT, S. E.; MAGNAN, G. M. The rhetoric and reality of supply chain management. International Journal of Physical Distribution \& Logistics Management, v. 32, n. 5, 2002. http://dx.doi.org/10.1108/09600030210436222

FAWCETT, S. E.; MAGNAN, G. M.; MCCARTER, M. W.A three-stage implementation model for supply chain collaboration. Journal of Business Logistics, v. 29, n. 1, 2008.

FISHER, M. L. What is the right supply chain for your product?. Harvard Business Review, v. 75, n. 2, 1997. 
FLINT, D. Strategic marketing in global supply chains: four challenges. Industrial Marketing Management, v. 33, n. 1, 2004. http://dx.doi.org/10.1016/j. indmarman.2003.08.009

GRIMSON, J. A.; PYKE, D. F. Sales and operations planning: an exploratory study and framework. International Journal of Logistics Management, v. 18, n. 3, 2007. http://dx.doi.org/10.1108/09574090710835093

HILLETOFTH, P.; ERICSSON, D. Demand chain management: next generation of logistics management. Conradi Research Review, v. 4, n. 2, 2007.

HILLETOFTH, P.; ERICSSON, D.; CHRISTOPHER, M. Demand chain management: a Swedish industrial case study. Industrial Management \& Data Systems, v. 109, n. 9, 2009. http://dx.doi.org/10.1108/02635570911002261

HOLWEG, M. et al. Supply chain collaboration: making sense of the strategy continuum. European Management Journal, v. 23, n. 2, 2005.

HORVATH, L. Collaboration: the key to value creation in supply chain management. Supply Chain Management: An International Journal, v. 6, n. 5, 2001.

JUTTNER, U.; CHRISTOPHER, M.; BAKER, S. Demand chain management-integrating marketing and supply chain management. Industrial Marketing Management, v. 36, 2007.

KAIPIA, R.; KORHONEN, H.; HARTIALA, H. Planning nervousness in a demand supply network: an empirical study. International Journal of Logistics Management, v. 17, n. 1, 2006. http://dx.doi. org/10.1108/09574090610663455

KATZ, J.; PAGELL, M.; BLOODGOOD, J. Strategies of supply communities. Supply Chain anagement: An International Journal, v. 8, n. 4, 2003.

KUMAR, N.; SCHEER, L.; KOTLER, P. From market driven to market driving. European Management Journal, v. 18, n. 2, 2000. http://dx.doi.org/10.1016/ S0263-2373(99)00084-5

LAMBERT, D. M. The eight essential supply chain management processes. Supply Chain Management Review, v. 8, n. 6, sep., 2004.

LAMBERT, D. M.; COOPER, M. C. Issues in Supply Chain Management. Industrial Marketing Management, v. 29, p. 65-83, 2000. http://dx.doi.org/10.1016/ S0019-8501(99)00113-3

LAMBERT, D. M.; COOPER, M. C.; PAGH, J. D. Supply chain management: implementation issues and research opportunities. The International Journal of Logistics Management, v. 9, n. 2, 1998. http://dx.doi. org/10.1108/09574099810805807

LANGABEER, J.; ROSE, J. Creating Demand Driven Supply Chains: How to Profit from Demand Chain Management.London: Spiro Press, 2002.

LAPIDE, L. Sales and operations planning Part III: a diagnostic model. The Journal of Business Forecasting, 2005.

LARSEN, T.S.; THERNOE, C.; ANDRESEN, C. Supply chain collaboration: theoretical perspective and empirical evidence. International Journal of Physical Distribution \& Logistics Management, v. 33, n. 6, 2003.

LEE, H.; PADMANABAHN, V.; WHANG, S. Information distortion in a supply chain: the bullwhip effect.
Management Science, v. 43, n. 4, 1997. http://dx.doi. org/10.1287/mnsc.43.4.546

MENTZER, J. T. et al. Defining supply chain management. Journal of Business Logistics, v. 22, n. 2, 2001. http:// dx.doi.org/10.1002/j.2158-1592.2001.tb00001.x

MENTZER, J. T.; FONGHIN, J. H.; GOLICIC, S. L. Supply chain collaboration: enablers, impediments and Benefits. Supply Chain Management Review, v. 4, 2000.

MENTZER, J. T.; MOON, M. A. Sales forecasting management: a demand management approach. Thousand Oaks: Sage, 2005.

MENTZER, J. T.; MOON, M. A. Understanding Demand. Supply Chain Management Review, v. 8, 2004.

MENTZER, J. T. et al. Demand Management. In: MENTZER, J. T.; MYERS, M. B.; STANK, T. P. Handbook of Global Supply Chain Management. California: Sage Publication, 2007.

MIN, S.; MENTZER, J. The role of marketing in supply chain management. International Journal of Physical Distribution \& Logistics Management, v. 30, n. 9, 2000. http://dx.doi.org/10.1108/09600030010351462

MIN, S. et al. Supply chain collaboration: what's happening? The International Journal of Logistics Management, v. 16, n. 2, 2005. http://dx.doi. org/10.1108/09574090510634539

PAIK, S. K.; BAGCHI, P. K. Understanding the causes of the bullwhip effect in a supply chain. International Journal of Retail and Distribution Management, v. 35, n. 4, 2007. http://dx.doi.org/10.1108/09590550710736229

PIRES, S. R. I. Gestão da cadeia de suprimentos:conceitos, estratégias, práticas e casos. São Paulo: Atlas, 2009.

PORTER, M. E. Vantagem competitiva: criando e sustentando um desempenho superior. Rio de Janeiro: Campus, 1989.

RAINBIRD, M. Demand and supply chains: the value catalyst. International Journal of Physical Distribution \& Logistics Management, v. 34, n. 3/4, 2004. http:// dx.doi.org/10.1108/09600030410533565

SABATH, R. E.; FONTANELLA, J.The unfulfilled promise of supply chain collaboration.Supply Chain Management Review, v. 6, n. 4, 2002.

SEIFERT, D. Collaborative plannning, forcasting and replenishment: how to create a supply chain advantage. New York: AMACOM, 2003.

SHETH, J.; SISODIA, R.; SHARAN, A. The antecedents and consequences of customer-centric marketing.Journal of the Academy of Marketing Science, v. 28, n. 1, 2000. http://dx.doi.org/10.1177/0092070300281006

SIMATUPANG, T. M.; SRIDHARAN, R. Benchmarking supply chain collaboration: an empirical study. Benchmarking: An International Journal, v. 11, n. 5, 2004

SIMATUPANG, T.; SRIDHARAN, R.The collaborative supply chain. International Journal of Logistics Management, v. 13, n. 1, 2002. http://dx.doi. org/10.1108/09574090210806333

SRIVASTAVA, R.; SHERVANI, T.; FAHEY, L. Marketing, business processes, and shareholder value: an organizational embedded view of marketing activities and the discipline of marketing. Journal of Marketing, v. 63, special issue, 1999. 
STANK, T. P.; KELLER, S. B.; DAUGHERTY, P. J. Supply chain collaboration and logistical service performance. Journal of Business Logistics, v. 22, n. 1, 2001. http:// dx.doi.org/10.1002/j.2158-1592.2001.tb00158.x

SVENSSON, G. Supply chain management: the re-integration of marketing issues and logistics theory and practice. European Business Review, v. 14, n. 6, 2002. http:// dx.doi.org/10.1108/09555340210448785

TAYLOR, D. H. Demand management in agri-food supply chains: an analysis of the characteristics and problems and a framework for improvement. The International Journal of Logistics Management, v. 17, n. 2, 2006. http://dx.doi.org/10.1108/09574090610689943

TAYLOR, D. H.; FEARNE, A. Towards a framework for improvement in the management of demand in agri-food supply chains. Supply Chain Management: An International Journal, v. 11, n. 5, 2006.

TRANFIELD, D. et al. Co-producing management knowledge. Management Decision, v. 42, n. 3-4, 2004. http://dx.doi.org/10.1108/00251740410518895

TRANFIELD, D.; DENYER, D.; SMART, P. Towards a methodology for developing evidence-informed management knowledge by means of systematic review. British Journal of Management, v. 14, 2003.

TROQUE, W. A. Influência das Práticas da Gestão da Cadeia de Suprimentos sobre a Gestão da Demanda: um Modelo de Análise Conceitual. Santa Bárbara D’Oeste. 2003. 189 f. Dissertação(Mestradoem Engenharia de Produção)-Faculdade de Engenharia, Arquitetura e Urbanismo, Universidade Metodista de Piracicaba, 2003.
VIEIRA, J.; YOSHIZAKI, H.; HO, L. Collaboration intensity in the Brazilian supermarket retail chain. Supply Chain Management: an international Journal, v. 14, n. 1, 2009.

VOLLMANN, T. E. et al. Manufacturing Planning and Control for Supply Chain Management. Boston: Mcgraw-Hill, 2004.

VOLUNTARY INTERINDUSTRY COMMERCE STANDARDS - VICS. Collaborative Planning, Forecasting and Replenishment (CPFRß): an overview 2004. Disponível em: <http://www.vics.org/ docs/guidelines/CPFR_Overview_US-A4.pdf $>$ Acesso em: 22 de dezembro de 2010.

VOLUNTARY INTERINDUSTRY COMMERCE SOLUTIONS - VICS. Linking CPFR and S\&OP: A Roadmap to Integrated Business Planning 2010. Disponível em: <http://www.vics.org/docs/committees/ cpfr/CPFR_SOP_Guideline_Ver1.0Sep2010.pdf> Acesso em: 29 de dezembro de 2010.

WALLACE, T. F. Sales \& Operations Planning: the how-to handbook. Cincinnati: T. F. Wallace \& Company, 2004.

WALTERS, D. Demand chain effectiveness supply chain efficiencies. Journal of Enterprise Information Management, v. 19, n. 3, 2006. http://dx.doi. org/10.1108/17410390610658441

WALTERS, D., RAINBIRD, M. The Demand Chain as an Integral Component of the Value Chain. Journal of Consumer Marketing, v. 21, n. 7, 2004. http://dx.doi. org/10.1108/07363760410568680 